\title{
LA EMPRESA EN EL CÓDIGO CIVIL Y COMERCIAL ARGENTINO
}

\author{
CRISTIAN RICARDO ABEL PIRIS \\ VERONICA MARIA LAURA GLIBOTA LANDRIEL
}

FACULTAD DE CIENCIAS ECONÓMICAS

UNIVERSIDAD NACIONAL DEL NORDESTE

ARGENTINA

"La inteligencia es la habilidad de adaptarse al cambio". Stephen Hawking. 


\title{
RESUMEN
}

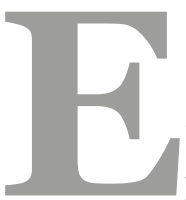

n el presente artículo realizamos un estudio sobre la empresa en el nuevo Código Civil y Comercial argentino. Iniciamos el trabajo efectuando un encuadre conceptual de la empresa en un intento por aprehender sus propiedades caracterizantes, y ponemos de manifiesto su enorme complejidad, y de allí las dificultades para ser captado de manera integral por el Derecho. Luego realizamos un relevamiento del modo que se ha sido tratado en el derecho argentino, y de su recepción legislativa en el nuevo Código de Derecho Privado. Finalmente criticamos la decisión legislativa de omitir un tratamiento exhaustivo de la empresa, sosteniendo que su relevancia actual justifica plenamente una regulación integral y no dispersa y atomizada tal como se encuentra el Código.

Palabras clave: empresa, organizaciones lucrativas, empresario, derecho empresario.

\begin{abstract}
In this paper we present a study on the business associations in the new Argentine Civil and Commercial Code. Work started making a conceptual frame of the business associations in an attempt to apprehend its characterizing properties, and we show its enormous complexity, and hence the difficulties to be captured comprehensively by the law. Then we conducted a survey of the way it has been treated under Argentine law, and legislative reception in the new Code of Private Law. Finally we criticize the legislative decision to omit an exhaustive treatment of the business associations, arguing that fully justifies its current relevance comprehensive regulation and not dispersed and fragmented as is the Code.
\end{abstract}

Keywords: business associations, profit organizations, businessman, corporate law.

\section{INTRODUCCIÓN}

Definir empresa desde el punto de vista jurídico no es una tarea sencilla porque parece no admitir conceptualizaciones dogmáticas capaces de contener toda su compleja realidad. Quizás esto sea así porque no se trate de un fenómeno originado en el Derecho, y de allí provengan las dificultades que actualmente existen para aprehender su contenido en las regulaciones normativas. 
La empresa es un fenómeno eminentemente económico, y es en la Economía donde debemos abrevar para identificar sus propiedades caracterizantes. Para Besil (2001) la empresa es un sujeto económico, y desde la perspectiva micro-económica es posible distinguir entre:

* Unidades de consumo: consumidor - familias.

* Unidades de producción: empresas.

* Entidades públicas: Estados.

Por su parte, Mochón y Becker (1999) explican que "la empresa es la unidad económica de producción encargada de combinar los factores o recursos productivos; trabajo, capital y recursos naturales, para producir bienes y servicios que después se venden en el mercado".

Según Fontanarrosa (1986), la empresa se caracteriza por ser económicamente:

* Una organización.

* Apta para producir bienes materiales e inmateriales (servicios).

* Destinados al cambio, es decir al mercado general.

* La actividad se realiza con el propósito de obtener beneficios.

A la luz de esos conceptos pareciera ser que la empresa solo produce, es decir genera bienes, pero esto no es cierto, también intermedia, distribuye o comercializa. Y en ambos casos su rol es fundamental, tanto al "crear" el bien como al "acercarlo" al consumidor. En el mismo sentido, vale aclarar que desde el punto de vista económico producir es crear utilidades, no solo fabricar productos (Fontanarrosa, 1986).

\section{IMPORTANCIA ECONÓMICA Y SOCIAL}

La empresa constituye una excelente muestra de la capacidad del hombre para organizarse e influir favorablemente en su entorno, aumentando la capacidad de la sociedad para producir bienes y hacerlos circular en el Mercado. Este fenómeno se vio impulsado desde el Renacimiento y tuvo su salto cualitativo a partir de la Revolución Industrial, con el florecimiento del capitalismo.

Como explica Drucker (1973), “en una economía estática no hay empresas comerciales o industriales... El intermediario de una sociedad estática es un corredor que recibe su compensación en la forma de un honorario, o un especulador que no crea valor", en tal sentido "una empresa comercial o industrial puede existir únicamente en una economía dinámica o por lo menos en la que considera natural y aceptable el cambio. Y la empresa es el órgano específico del crecimiento, la expansión y el cambio".

Fontanarrosa (1986) afirma que la producción organizada es casi tan vieja como la humanidad, o por lo menos desde que el hombre se hizo gregario. Pero su forma tan rudimentaria y sus escasos aportes hicieron que ni el Derecho ni la Economía repararan en ella en el estadio agrario 
pre-industrial. Sólo una vez que se perfeccionó la empresa en cuanto organización, y se mejoró su desenvolvimiento y prestaciones, empezó a cobrar centralidad para estas dos ciencias.

Sostiene Vítolo (1998), que en los países industriales de occidente, la empresa privada ha sido el principal instrumento de desarrollo económico y de cambio social, que se ha operado desde la revolución industrial hasta nuestros días. En este sentido, la sociedad de consumo sería impensable sin el desarrollo explosivo de la empresa.

En la actualidad, ya en una etapa postindustrial -igualmente llamada segunda revolución industrial, revolución tecnológica, etc.-, la empresa continúa mostrando todo su potencial y capacidad de adaptación. Vale decir, no debe concebirse solo como un fenómeno de la sociedad industrial, sino de cualquier sociedad caracterizada por el dinamismo.

Desde el Análisis Económico del Derecho, Richard Posner (1998) utiliza el concepto de costos de transacción para explicar la importancia de la empresa. Los costos de transacción son los derivados de “...descubrir con quién deseamos transar, informar a la gente que deseamos intercambiar y en qué términos, conducir negociaciones que lleven a un convenio, redactar el contrato, llevar a cabo la inspección necesaria para asegurarnos de que los términos del contrato se observan. Estas operaciones son, a menudo, muy costosas; suficientemente costosas para evitar muchas transacciones..." (Coase, 1991, p. 98). Es decir, los costes de transacción incluyen, los de información, que son aquellos derivados de la búsqueda e identificación de los agentes con quienes contratar; los de negociación, que comprenden acordar y redactar las cláusulas del contrato; y los de garantía, derivados de la necesidad de asegurar el cumplimiento de lo acordado y protegerse de las consecuencias negativas del incumplimiento. En ese sentido, la empresa es exitosa como modelo de organización, porque reduce los costos de transacción internos. De otro modo, si el empresario debiera contratar uno a uno y en cada caso por cada factor de producción que requiera para la elaboración de un producto, eso resultaría ineficiente. La empresa es eficiente porque crea un sistema que reduce los costos de transacción y organiza la producción.

Vítolo (1998) señala asimismo la importancia social de la empresa, cuestión que ha empezado a remarcarse desde la sociología y la teoría de los sistemas desde la segunda mitad del siglo XX. Desde este punto de vista, la empresa es vista como organización, pero ya no como un sistema cerrado, es decir como un ente aislado que está produciendo a un costado de la sociedad, sino como un sistema abierto que interactúa constantemente con el contexto, del que recibe insumos (ingresos) y al que provee productos y servicios (egresos). Esto lleva posteriormente al estudio de la interacción del sistema-comercio con los subsistemas-empresas, y la relación entre poder (empresarial) y responsabilidad social. 


\section{IMPORTANCIA JURÍDICA}

Es tal su relevancia para el Derecho Comercial, que han existido intentos por refundar a esta rama del Derecho Privado, centrado en la empresa -en tanto estructura y actividad organizada-, entendiendo por tanto al derecho mercantil como el derecho de la empresa.

Para Farina (1997), el "derecho mercantil es la rama del derecho privado que regula la organización y los elementos de la empresa, la actividad de los empresarios mercantiles en cuanto tales, así como las relaciones jurídicas de derecho privado derivadas de la actividad externa que aquellos desarrollan en cumplimiento del objeto para el cual la empresa fue creada".

Recordemos que el mérito de haber formulado la teoría que identifica el derecho mercantil con el derecho de la empresa corresponde a Wieland, quien sostiene que la organización de los factores de la producción constituye el núcleo central de las actividades mercantiles. Y que las mismas se han transformado en el ámbito natural de aplicación de las normas que regulan las principales actividades comerciales (FARINA; 1997).

Se deja atrás de cierto modo, la idea de concebir al derecho mercantil como el derecho de los actos aislados, convirtiéndolo en el derecho de las organizaciones empresarias.

Luego Mossa, recogerá el guante, distinguiendo en esta línea de análisis, que debe interpretarse al derecho comercial desde la idea de empresa comercial, sentando las bases para entender la organización empresaria como un concepto más amplio y omnicomprensivo que el de la mera actividad de producción o comercialización.

En síntesis, el derecho comercial sólo captaría el fenómeno de la empresa, cuando ésta resultara una organización mercantil actuando en el mercado, dejando fuera una pléyade de estructuras organizacionales que no realizarían actividades que encuadren en ese ámbito (agrarias, mineras, civiles, administrativas, etc.).

Ascarelli por su parte, sostiene que los principios del Derecho Comercial se relacionan con una economía de masa, que trasciende la propiedad privada de los instrumentos de producción. Esto, de alguna manera borra ciertas fronteras, habilitando la irrupción de la actividad empresaria del Estado, asociaciones, mutuales, cooperativas, etc., reafirmando una nueva concepción del término, y llevándolo a nuevos y más elásticos límites.

Desde otro punto de vista, ha quedado más que aceptada la idea según la cual el concepto de empresa es puramente económico, y que los intentos para introducirlos por el tamiz de las ciencias jurídicas han fracasado.

Tampoco debemos olvidar que en el estado actual de cosas, la regulación del fenómeno empresario ha sido parcializada (atomizada al decir de Etcheverry), y cada rama del Derecho ha tomado para sí cuestiones o circunstancias particulares del mismo. Es que ¿acaso alguien duda que pueda restarse al derecho laboral la regulación de los vínculos derivados del trabajo en relación de dependencia que sostiene en gran medida la existencia de toda organización? 
Finalmente, sea la empresa el campo exclusivo y excluyente del derecho mercantil o no, nadie puede negar su centralidad y gravitación en el derecho comercial moderno. Y a esto dedicaremos la segunda parte del presente trabajo cuando analicemos el impacto del Código Civil y Comercial en la regulación de la empresa.

\section{CONCEPTO DE EMPRESA}

La Real Academia lo define en una acepción como "entidad integrada por el capital y el trabajo, como factores de la producción y dedicada a actividades industriales, mercantiles o de prestación de servicios con fines lucrativos y con la consiguiente responsabilidad". Por un lado, es una definición muy abarcativa, dado que comprende fin lucrativo y el riesgo es del empresario que según Etcheverry (2005) corresponde al empresario y no a la empresa, pero por otro lado es restrictiva, dado que reduce los factores productivos solo a capital y trabajo, y limita el tipo de empresas a industriales, mercantiles y de servicios.

La cuestión de la ganancia o rentabilidad como elemento característico de la empresa es muy discutido.

Druker (1973) explica que no es posible definir empresa por referencia a la ganancia. Que está variable no sirve de explicación, causa o justificación de la empresa, y que a lo sumo es prueba de su validez. En la realidad, en tren de la subsistencia, cualquier empresa aspira a la obtención de una utilidad suficiente para cubrir los riesgos de la actividad económica, y de ese modo, evitar pérdidas; pero de ahí a derivar que su razón de ser es la ganancia, conlleva un paso bastante largo.

Siguiendo este hilo argumental, si no es la ganancia el elemento distintivo de la empresa ¿̇cuál es? El autor austríaco lo encuentra en la comercialización, y lo explica del siguiente modo: "la comercialización es la función distintiva y original de la empresa. Una empresa se distingue de todas las restantes organizaciones humanas por el hecho de que comercializa un producto o un servicio. No es lo que hace la Iglesia o el ejército, la escuela o el Estado. Cualquier organización que se realiza mediante la comercialización de un producto o servicio configura una empresa. Cualquier organización en la cual la comercialización falta o es un elemento incidental no constituye una empresa..." (Drucker, 1973).

Para disipar dudas, igualmente explicaba que la ganancia (motivo de utilidad) tampoco es el elemento empíricamente considerado como caracterizante del empresario, sino que esta idea fue incorporada por los economistas clásicos para explicar la realidad económica que no podía justificarse con su teoría del equilibrio estático.

La empresa como figura jurídica resulta problemáticamente conceptualizable. Según Etcheverry (2005), el término es del siglo XIX pero el concepto es del siglo XX. Algunos auto- 
res coinciden en que no existe una definición legal que la englobe o pueda englobarla por su complejidad.

Los juristas se han esforzado por elaborar un concepto jurídico de empresa, pero aquí han aparecido dos cuestiones fundamentales: por un lado, el reduccionismo que surge cuando se pretende definir empresa por alguna de sus manifestaciones, pretendiendo definir el todo por una de sus partes. En ese caso es posible brindar un concepto jurídico que recorte el fenómeno empresa, pero la crítica vendrá dada por su valor practico. Por otro lado, puede sostenerse que es deseable que tanto el Derecho como la Economía remitan al mismo fenómeno de la realidad social, para ello sería necesario un concepto jurídico de empresa, que se construya sobre la realidad económica. Pero en ese supuesto la dificultad viene dada por el problema que resulta de aprehender una realidad tan amplia y dinámica en un concepto estático.

Otro problema es el intento de los juristas por trasladar la discusión sobre la naturaleza jurídica a la definición de empresa. Las discusiones sobre naturaleza jurídica son cuestionables en sí mismas, porque parten de la base de suponer que las cosas tienen una esencia pura, una naturaleza inmanente que está allí presente y que debemos descubrir, lo cual es simplemente falso. Una faceta más constructiva del asunto se da cuando - aún bajo el manto de la discusión sobre la naturaleza jurídica- se pretende hacer taxonomías, y es así que se intenta definir "por género próximo y diferencia específica”. Esto tiene valor práctico porque al ser la institución parte de una categoría más general, es posible determinar que sus normas particulares rigen la institución, pero en todo lo no previsto es necesario remitirse a las normas que regulan el género, como un modo de resolver lagunas o contradicciones. Desde ese punto de vista se pretende definir a la empresa como persona jurídica, ente, o bien, como patrimonio separado, etc., pero el quid del problema es la insuficiencia de nuestras categorías jurídicas clásicas para aprehender ese fenómeno económico.

Las dos categorías entre las cuales fluctuaría la naturaleza jurídica de empresa son los conceptos de sujeto de derecho y patrimonio, pero ambos resultan inadecuados porque las categorías jurídicas son redes para atrapar datos de la realidad y procesarlos, y si el dato es demasiado grande rompe la red, pero es demasiado fluido pasa a través de ella. La realidad de la empresa rompe con los esquemas jurídicamente aceptados.

Finalmente pensamos que, desde un punto de vista práctico, si la disciplina jurídica pretende captar y regular íntegramente a la empresa, no debe hacer recortes o modificaciones conceptuales para lograr adaptarla a los moldes del Derecho, sino que tiene que tomarla y reconocerla tal cual es en su ámbito específico que es la economía. Pero quizás allí nos topemos con una dificultad insalvable, la cuestión que "la empresa es sólo un supuesto de hecho y no un concepto traducible al mundo jurídico" (WUERDINGER).

Hechas estas aclaraciones, es conveniente reparar en los intentos de Vítolo (1998), por definir empresa de un modo dinámico. Este autor la incluye dentro del género de las organizaciones, pero no hace referencia a la vieja teoría sostenida por Ferrara, Vivante, Broseta Pont, 
etc. que concebían a la empresa sólo como una organización de factores productivos, es decir la organización como acción de reunión y coordinación de los mismos.

La teoría de la organización es mucho más moderna y ve a la organización como ente, afirma que "una organización es un ente social identificable que persigue objetivos múltiples, a través de las actividades y relaciones coordinadas entre objetos y personas”, organización es el género, y existen muchas especies por ejemplo las organizaciones gubernamentales, no gubernamentales (no lucrativas) y privadas (lucrativas). Toda organización tiene objetivos, personas, objetos, y establece un sistema formal de estructuración que asegure coordinación y estabilidad.

La diferencia especifica sería considerar a la empresa como una organización cuyo objetivo es la de generar utilidades, a través de actividades de producción de bienes materiales o inmateriales y/o intermediación, que cuenta con las personas y objetos necesarios para la consecución de sus objetivos (factores de producción) y articula un sistema de estructuración que le otorgue coordinación y estabilidad para el logro de éstos.

Esta concepción, sin embargo, no es propiamente jurídica, ya que no existe la categoría organización en el derecho, pero tiene la ventaja de que no se opone a las prescripciones normativas. Según Vítolo (1998) para nuestro derecho la empresa no puede ser considerada desde las corrientes subjetivistas, por tanto no es un sujeto de derecho. Esta es además, la postura dominante en la doctrina argentina.

\section{LA EMPRESA EN EL DERECHO ARGENTINO ANTES DEL CÓDIGO CIVIL Y COMERCIAL}

Recordemos que el artículo 8 del Código de Comercio enumeraba los actos de comercio, en una descripción legal de todo lo que debía ser considerado materia mercantil, y en cuya enunciación se incluía la empresa, dando lugar a la prolífica crítica doctrinaria que esgrimía una verdad de Perogrullo: la empresa no es un acto. Sin perjuicio de ello, resultaba comprensible el error, en orden a que deriva de la fuente inmediata del Código francés de 1807, donde la empresa aparece por primera vez y como acto de comercio (Garrone, 1986).

El mencionado art. 8 , inc. $5^{\circ}$ del Código de Comercio, hacía alusión a "las empresas de fábricas, comisiones, mandatos comerciales, depósitos o transportes de mercaderías o personas por agua o por tierra”. Es decir que el Código no se refería a la empresa en general, sino a cinco categorías definidas, que eran a la postre las empresas más conocidas y usuales a la época de su sanción. Lo común en este inciso es que la caracterización de comercial viene dada por el particular modo de organización de la actividad: la empresa. Es decir no interesa la actividad en sí (fabricación, depósito, transporte, etc.), sino el modelo organizativo.

No existía una definición de empresa en el Código de Comercio, y tampoco normas que 
permitieran señalar una regulación sistemática del fenómeno. No obstante, quedaba claro que no toda empresa económica era comercial, quedando fuera de regulación las agropecuarias y mineras que, aún siendo empresas en todo el concepto económico, no eran tratadas como tal por el Código de Comercio.

Por lo expuesto, la doctrina y jurisprudencia que reconocieron de antaño que la enumeración del art. 8 era meramente enunciativa, fueron ampliando el campo de aplicación de la norma, incorporando a la materia comercial la organización empresaria que realiza actividades como: molinos, tintorerías industriales, espectáculos públicos con fines de lucro, sanatorios, hoteles, empresas periodísticas con fines lucrativos, educación privada, e incluso se extendió a las empresas constructoras. Recordemos al maestro Halperin (1994), cuando infiere que por vía jurisprudencial "toda interposición organi-zada en la prestación de servicios con fin de lucro, constituye una empresa mercantil”.

No podemos dejar de señalar el dato paradójico que, siendo la empresa una cuestión nodal en el Derecho Comercial, no era posible encontrar un concepto legal de empresa en esta rama jurídica, pero si en el derecho laboral, que en el art. 5 de la Ley 20.744, define empresa en estos términos: "organización instrumental de medios perso-nales, materiales e inmateriales, ordenados bajo una dirección para el logro de fines económicos o benéficos”.

\section{LA EMPRESA EN EL CÓDIGO CIVIL Y COMERCIAL}

Antes de entrar de lleno al análisis del tratamiento de la empresa en el Código Unificado, debemos mencionar la crítica que desde numerosos sectores de la ciencia jurídica se le ha opuesto al modelo de codificación elegido, en orden a que contraría la directiva constitucional que exige una legislación diferenciada entre la materia civil y la comercial, sea en textos separados o unificados -prevista en el artículo 75 inciso 12 de la Constitución Nacional-; en tanto el texto en análisis no mantiene al derecho comercial como categoría diferenciada del derecho civil, con sus propias normas delimitativas y normas preceptivas (Favier Dubois (p) - Favier Dubois (h); 2013).

De allí que el derecho comercial se mantendría vigente en supuestos excepcionales, que tienen que ver con la incorporación de principios del derecho mercantil como regla en materia de obligaciones y contratos (presunción de onerosidad, por ej.), y en la vigencia de leyes especiales que regulan aspectos concebidos como eminentemente mercantiles (transferencia de fondos de comercio; sociedades; seguros; marcas y patentes; derecho de la competencia; entre otros).

Como expresáramos más arriba, la noción de empresa como centro del sistema de derecho comercial ha sido planteado por los comercialistas como un triunfo y un salto evolutivo, pero hoy se aparece como materia "olvidada" en el texto del novel corpus iuris, lo que califican 
con distintos grados de desagrado como un tópico pendiente, omisión deliberada, "pecado nominalista" (FAVIER DUBOIS) o un camino desandado en el nuevo código unificado del Derecho Privado argentino.

La idea que nos moviliza en este punto, es intentar analizar desde la evolución histórica que ha sufrido el concepto y la concepción de la empresa, si su regulación sistematizada debiera ser propia de un código de estas características o si resulta sano haber mantenido el silencio, y que cada aspecto de este instituto económico sea captado por las ramas del Derecho que resulten competentes.

Sucede que en el nuevo Código Civil y Comercial, aprobado por Ley 26994 y su modificatoria, Ley 27077 -que anticipa su entrada en vigencia-, no se ha receptado en este punto el clamor que parte de la doctrina comercialista venía expresando respecto de la necesidad de incorporar al texto expreso, disposiciones que pudieran comprenderse como una especie de "estatuto de la empresa y del empresario", cuestión que se venía zanjando a través de la interpretación doctrinaria y jurisprudencial de las disposiciones del Código de Comercio relativas al estatuto del comerciante en concordancia con la normativa en materia societaria.

Tampoco se ha traslado la noción de comerciante tradicional, y del estatuto reconocidamente expresado en el Código de Comercio, se mantienen algunos deberes, pero respecto de sujetos disímiles.

Frente a ello, nos proponemos desentrañar si en el texto legal aludido existe una concepción de empresa, y en su caso, si la misma respeta o recupera en parte aquella más arraigada en la doctrina argentina contemporánea.

Frente a este panorama, nos encontramos con un nuevo ordenamiento de derecho privado que hace mutis por el foro, y no incorpora más que nominalmente a la empresa, al referirse a los sujetos que resultan obligados a llevar contabilidad y confeccionar estados contables (art. 320 y ss. CCC); y aún, sin nombrarla, al referenciar regulando fenómenos de organización empresaria derivados de los contratos asociativos (Libro III, Título IV, Capítulo 16 del CCC.); o bien, a través del mantenimiento de la vigencia de la ahora denominada Ley General de Sociedades y la incorporación de la figura de la sociedad anónima unipersonal, al art. $1^{\mathrm{o}}$, L.G.S.

También se menciona el término, al definir el contrato de consumo, en el art. 1093, como aquel "celebrado entre un consumidor o usuario final con una persona física o jurídica que actúe profesional u ocasionalmente o con una empresa productora de bienes o prestadora de servicios, pública o privada, que tenga por objeto la adquisición, uso o goce de los bienes o servicios por parte de los consumidores o usuarios, para su uso privado, familiar o social".

Implícitamente, recepta la noción de empresa familiar, en el art. 1010, introduciendo la posibilidad de celebrar acuerdos entre los socios destinados a establecer el destino de la organización frente al fallecimiento de los mismos, siempre que se salvaguarden los derechos de los herederos legítimos. Sostiene la norma: "Los pactos relativos a una explotación productiva o a participaciones societarias de cualquier tipo, con miras a la conservación de la unidad 
de la gestión empresaria o a la prevención o solución de conflictos, pueden incluir disposiciones referidas a futuros derechos hereditarios y establecer compensaciones a favor de otros legitimarios. Estos pactos son válidos, sean o no parte el futuro causante y su cónyuge, si no afectan la legítima hereditaria, los derechos del cónyuge ni los derechos de terceros”.

No podemos dejar de traer a colación que, la redacción del artículo mencionado en primer lugar (art. 320 CCC), como su tratamiento dentro de la teoría general de los hechos y actos jurídicos, deviene una copia fiel del proyecto de Código de 1998 (art. 302), -que a su vez se inspiró en los Proyectos de Código Único de 1987 y los de 1993 (el de la Comisión Federal y el de la Comisión designada por decreto 468/92)-, y de cuyos fundamentos tampoco se decanta noción alguna vinculada a la empresa.

Que no exista una definición legal de empresa, no debe llevarnos a pensar que la misma no sea objeto de regulación normativa. Por el contrario, podemos encontrar normas que seguramente facilitarán la actividad empresarial, por ejemplo, las que brindan mayor impulso a formas alternativas de resolución de conflictos, lo que ahorrará costos y tiempo a los agentes económicos.

En la misma línea, se consagra el principio de libertad de contratación (art. 958) y de negociación (art. 990), regulando expresamente los límites de la responsabilidad precontractual, y asegurando a las empresas poder negociar con tranquilidad, sin riesgo de responsabilidad, salvo interrupciones de mala fe. Además se asegura que toda información confidencial tratada en la negociación está protegida por un principio de reserva (art. 992), que permanece vigente aunque no se llegue a celebrar el contrato. Estas prescripciones permiten inferir un marcado interés de los mentores del Código Civil y Comercial hacia la captación de la actividad empresaria.

Asimismo, y en lo que respecta al tema en análisis, no podemos dejar de mencionar el paradigma de la constitucionalización del derecho privado, que aparece manifiesto, entre otras normas, en la que establece que lo todos los derechos resultantes de los contratos integran el derecho de propiedad del contratante (art. 965), eso significa nada menos que brindar la máxima protección constitucional, de modo tal que limita la intervención del legislador y del juez en lo estipulado contractualmente. La propiedad es inviolable sostiene el art. 17 de la CN, y sin dudas brindará seguridad jurídica a las empresas.

Toda la materia de contratos es supletoria de la voluntad de las partes (art. 962) y subsisten muy pocas normas imperativas. Por lo que se amplía el campo de acción de las empresas en los contratos negociados, brindando mayores posibilidades de regulación de los propios derechos.

Se incluye la tipificación de un amplio abanico de contratos que son muy utilizados por las empresas, tales como agencia, concesión, franquicia, factoraje, fideicomiso, etc., que, si bien se trata de normas supletorias en su mayoría, brindan la ventaja de asegurar un marco de certeza en las relaciones negociales.

Por otra parte, se consagra la "previsibilidad del daño contractual" (art. 1728), eso quiere decir que en el contrato se responde por los daños previsibles a la hora de contratar. 
Se incorpora un capítulo entero sobre las reglas que rigen en el derecho internacional privado, tendiente a brindar mayores certezas a las empresas importadoras o exportadoras, o en general, a todas aquellas que sean parte en contratos internacionales.

Además se regula de manera especial los contratos conexos (arts. 1073 a $1075 \mathrm{CCC}$ ), fenómeno muy extendido en la práctica empresarial, consistente en vincular contratos entre si generando una red contractual que debe ser interpretada como una unidad. Las previsiones del código tienden a evitar abusos con la utilización de esta modalidad, particularmente frente a consumidores.

En el campo de las sociedades, que ya no son comerciales, sino sociedades en general, se introducen modificaciones a la ley 19.950 para habilitar la sociedad unipersonal. Un tipo de sociedad anónima de un solo socio, lo cual favorecerá las inversiones y hará innecesarias esas fantasías de sociedades con un socio poseedor del 99\% de los acciones.

Igualmente las empresas familiares se verán beneficiadas al posibilitarse una mejor programación patrimonial y sucesoria, con el pacto de herencia futura, la reducción de la legítima hereditaria, el valor del protocolo familiar como contrato y la opción por matrimonio con separación de bienes, entre otras medidas.

Otra cuestión, que también pude verse como excepción al tratamiento unificado para civiles y comerciantes, está dada por la imposición de una contabilidad solo a las personas jurídicas privadas y a ciertas personas humanas, con aparente fundamento en la actividad empresaria desarrollada (artículo 320, CCC), tema que alude y roza el tópico de análisis en este trabajo.

\section{7. ¿CREACION DE UN ESTATUTO ESPECIAL PARA LOS EMPRESARIOS?}

Hasta aquí, surge de la exposición realizada, que el nuevo código nos ofrece una serie de normas dispersas, en las que orienta la regulación expresamente hacia las empresas, caracterizándolas -en algunas de ellas-, como organizaciones destinadas a la realización de actividades económicas, pero sin establecer lineamientos generales sobre el instituto, manteniendo sobre esta cuestión la misma línea que ofrece el Código de Comercio -que resultó desbordado por la evolución experimentada, persistiendo en la regulación del comerciante individual a través de la interpretación superadora de la doctrina y jurisprudencia-.

Opinan algunos autores que la mentada omisión de regulación sistemática y expresa del estatuto de los empresarios, resulta meramente "nominativa", en orden a que del análisis de los arts. 320 y siguientes y concordante del Código Civil y Comercial, la Ley General de Sociedades y otras normas comerciales especiales no derogadas, se desprende la existencia de deberes específicos para los empresarios, como son los de llevar contabilidad, la publicidad de 
ciertos actos en un Registro, o la existencia de mandatos aparentes a favor de administradores que se encuentren al frente del establecimiento abierto al público (factores), dependientes propiamente dichos o de aquellos que entreguen mercaderías fuera de él (viajantes), previstos en el art. 367, incs. a, b y c, CCC.

Deberes que además, se extienden a otros sujetos sin fines de lucro, como las asociaciones (art. 169, CCC.) (Favier Dubois (p) - Favier Dubois (h); 2014); y que se complementan con los otrora propios del comerciante (rendición de cuentas; correspondencia comercial, etc.), que se establecen en la nueva norma trascendiendo a todos los sujetos del Derecho Privado cuando quedan comprendidos en las situaciones previstas (así, la obligación de rendir cuentas se regula como obligación genérica en el Libro III, Capítulo 3, como una clase de obligación, en la Sección $11^{\mathrm{a}}$, desde el art. 858 al 864, CCC; en tanto la correspondencia como instrumento de prueba de los actos jurídicos en general aparece regulada en el Libro I, Titulo IV de los hechos y actos jurídicos, Sección $6^{\text {a }}$ referida a los instrumentos privados y particulares, en los arts. 318 y 319, CCC.).

\section{LA DEFINICION DE EMPRESARIO A PARTIR DE LA INTERPRETACIÓN DEL ARTICULO 320 CCC}

Partimos de la concepción del empresario como sujeto titular de todas las relaciones jurídicas inherentes a la existencia y desarrollo de la actividad y responsable de la empresa, en tanto la organiza, dirige, explota y percibe sus resultados.

Sin embargo, este concepto ha evolucionado en el mundo: de la situación de empresario capitalista, promotor, propietario y administrador, a una concepción de empresario profesional, que solo promueve y administra a la empresa, sin ser su dueño. Hacia esa concepción se dirige el novel corpus iuris, al describir expresamente las distintas situaciones jurídicas que pueden dar lugar a la figura del empresario y su responsabilidad frente a los deberes legalmente impuestos.

Sostienen los Favier Dubois (2013) que "históricamente, las funciones del empresario pasaron de ser el suministrador del capital (teoría de Carlos Marx) a otras: organizador de los restantes factores de producción, tomador de decisiones dentro de la estructura empresarial, tomador del riesgo del negocio".

Cuando las funciones descriptas están fragmentadas entre distintas personas, o cuando el empresario no aporta capital porque lo toma prestado de terceros, cuando traslada el riesgo mediante múltiples instrumentos jurídicos (seguros, opciones, derivados, etc.), y cuando traslada la organización económica y las decisiones a asesores, mandatarios o empleados, ¿qué es lo que define al empresario?

Lo que lo define es ser "el centro" de una serie de contratos -entre los que figuran los referidos en el párrafo anterior-, mediante los cuales la empresa adquiere su configuración. 
Por su parte, para el derecho laboral lo que define al empresario es la dirección y organización de la empresa, conceptualizándolo la ley de contrato de trabajo como quien "dirige la empresa por sí, o por medio de otras personas" (art. 5, ley 20.744).

\section{ORGANIZACIÓN Y EMPRESA}

Abrimos un paréntesis en este punto, para sentar algunas premisas acerca de la interpretación que cabe hacer del artículo 320 CCC, en virtud de que consideramos que ha sido redactado con técnica legislativa que induce a interpretaciones poco claras, pero permite introducir el tema que nos ocupa.

El artículo de mención reza en su parte pertinente: “.... están obligadas a llevar contabilidad todas las personas jurídicas privadas y quienes realizan una actividad económica organizada o son titulares de una empresa o establecimiento comercial, industrial o de servicios...”. En este acápite, habría que analizar y desentrañar qué diferencia existe entre quien organiza la actividad económica y el titular de una empresa.

Es claro que la norma de mención, dispone un particular deber a cargo de quien debe considerarse el aspecto subjetivo de la organización, pero no resulta tan claro si se pueda englobar a todos los sujetos o personas en el concepto tradicional de "empresario".

Por otra parte, se vuelve a plantear el dilema respecto de qué debe entenderse por empresa, en función de la amplitud de sujetos que quedan comprendidos en la obligación legal de llevar una contabilidad en los términos legales.

Veamos hacia donde nos lleva el análisis que proponemos: si concebimos que la noción de empresa puede extrapolarse del mundo meramente mercantil, dando lugar a organizaciones que no tienen como objeto fundamental la producción o intercambio de bienes y servicios para el lucro, entonces es posible que aceptemos que toda persona jurídica privada, per se, podría ser entendida como empresario; en tanto si fuera una persona humana, para considerarse tal, debiera ser organizador o titular de una actividad económica organizada.

Como puede apreciarse el artículo establece una obligación legal de llevar contabilidad, pero de su texto podríamos colegir esta distinción: si se es persona jurídica privada se presume su carácter de organización, en tanto si se es persona humana habrá que demostrar que se actúa organizadamente para imponerle el deber de llevar su contabilidad en los términos y formas establecidas por la norma.

Entonces, cabe formularse la pregunta ¿̇cuál es el fundamento para imponerle la obligación de llevar y confeccionar sus estados contables a, no digamos las sociedades en general, sino a asociaciones, fundaciones, consorcios de propiedad horizontal, etc., si no es entender que las mismas son personas jurídicas que ejercen ciertas actividades vinculadas al Mercado y que os- 
tentan naturalmente la forma de una organización?

Si lo analizamos a contrario sensu, surge del propio texto del artículo que "quedan excluidas de las obligaciones previstas en esta Sección, las personas humanas que desarrollen profesiones liberales o actividades agropecuarias y conexas no ejecutadas u organizadas en forma de empresa". Dada su organización a partir de un plan de acción económica, surge la obligación de llevar cuenta de su actividad.

Este es el punto de inflexión: si no se tiene forma externa de organización, no se considera empresa, y por ende, no queda obligado su titular.

"Con relación a este aspecto, efectivamente se recomienda y propone que todas aquellas personas y/o entidades que manejen y tengan a su cargo patrimonios propios o de terceros de cierta y significativa importancia relativa estén alcanzados por la presente normativa, y consecuentemente deban mantener y llevar un sistema contable conforme con las prescripciones legales establecidas" (Dell'Elce, Q.).

Frente a ello, debemos recuperar la ardua discusión filosófica acerca de si resulta acertado identificar organización con empresa, o si, a partir de la interpretación de los sujetos obligados por esta norma, debemos pensar la relación entre ambos términos como de género y especie.

Pues bien, nadie controvierte la idea de empresa como el ejercicio profesional de una actividad planificada, a partir de una finalidad u objetivo, y con una unidad económica organizada en la cual ejerce su actividad profesional el empresario por sí mismo o por medio de sus representantes.

En ese hilo argumental, tampoco es posible excluir ese concepto del de organización. Este último se construye sobre la representación de una institución social, en la que el conjunto de sus integrantes desempeñan un sistema de actividades, coordinado de forma conciente y con racionalidad limitada, en la búsqueda de determinados objetivos; este conjunto de actividades conforma su estructura. (Hernangomez Barahona).

Ahora bien, ¿̇es posible distinguir este concepto general del de empresa? Al decir de este autor, existen una serie de variables que permitirían concluir en que la empresa constituiría un tipo determinado de organización que se distinguiría por la existencia de determinados objetivos y el desempeño de un sistema concreto de actividades.

Los objetivos podrían distinguirse en básicamente económicos (beneficios, crecimiento, seguridad y supervivencia), de los no económicos (políticos, sociales, culturales, deportivos, etc.). En cuanto a las actividades, cabría plantear la misma distinción: actividades económicas (extracción, producción, distribución de bienes), y no económicas (el consumo, por ej.).

De la conjunción de ambas variables, cabría decantar a las empresas como aquellas organizaciones que realizan primordialmente actividades económicas, fundadas en objetivos del mismo tipo.

Esto que resulta tan sencillo en la teoría, no se traduce a la realidad, en la que nos encontramos con una línea que se vuelve cada vez más borrosa al separar las tradicionales organiza- 
ciones sin fines de lucro y destinadas a objetivos primordialmente no económicos (asociaciones por ejemplo), de las sociedades típicas.

Además, actividades idénticas pueden tener diferentes caracteres en función de los objetivos: así, una actividad como la investigación puede ser considerada como no económica si se desarrolla en un ámbito universitario o de una organización científica, pero será indudablemente económica si se da en el ámbito de la producción de bienes y en ambos casos, estaremos hablando de la misma actividad con distintos objetivos. Puede suceder lo contrario, que los objetivos sean claramente no económicos, en tanto las actividades tengan ese carácter prioritario (como es el caso de una empresa estatal de servicios públicos). Estos supuestos, son los que plantean la discusión y la necesidad de sentar bases para entender si hablamos de empresas en estos casos o de simples organizaciones no empresariales.

Esta discusión tiene sentido en nuestro trabajo, para intentar desentrañar si la regulación que ofrece el nuevo código referente a las empresas y empresarios permite entender cual es la idea de empresa que lo atraviesa.

Volvemos entonces al principio: si al establecer como obligación legal llevar la contabilidad, el nuevo texto legal reúne como sujetos obligados a las personas jurídicas privadas, sin distinción de objetivos ni actividades, entonces, debemos colegir que para este nuevo ordenamiento, la visión de empresa se inclinaría mas hacia la sinonimia con la de organización, que con aquella que postula una vinculación de género a especie entre estas dos figuras.

\section{CONCLUSIONES}

Haciendo un breve racconto histórico podemos ver un marcado contraste entre el pobre tratamiento dispensado por el Código de Comercio a la empresa y su importancia económica, lo que se explica extrapolándonos al tiempo y espacio de su redacción. Los hombres que sancionaron nuestra constitución, y nuestros códigos tenían visión estratégica. En ese entonces nuestro país tenía potencialidad para desarrollarse como potencia agro exportadora, no industrial o manufacturera. Entonces, dado que la riqueza estaba en la tierra y en sus frutos y productos, no fue casual que el derecho real mejor tratado fuera el de dominio, la obligación más extensamente reglamentada fuera la de dar cosas, y el contrato más sesudamente desarrollado el de compra-venta.

En ese contexto histórico era comprensible la razón por la cual la empresa resultaba mencionada de modo incidental, justamente, porque su desarrollo no era vital en ese contexto. La empresa comercial no era importante para una economía de base agraria, y a mayor abundamiento nos basta con recurrir al art 452 del Código de Comercio para ver que fueron excluidas de la materia comercial toda negociación referida a inmuebles, cosechas y ganados. 
Lo expuesto nos marca desde otra perspectiva, lo incomprensible de mantener casi incólume una estructura jurídica pensada para un país de otro tiempo. Ya en el siglo XX la empresa cobró otra importancia por lo que resultaba prioritario avanzar y redefinir institutos, y donde la empresa dejara de ser una institución jurídica periférica para tomar la centralidad que adquirió en la economía del país. Hacia allí se encaminaron las interpretaciones doctrinarias y jurisprudenciales, transformando paulatinamente el con-cepto de comerciante al de empresario.

Sin embargo, en el Código Civil y Comercial recientemente sancionado no hallamos una estatuto de la empresa, por el contrario se ha optado por un tratamiento disperso y atomizado, y las normas referidas a los deberes a cargo de los empresarios resultan poco claras en cuanto a quienes deben ser entendidos como tal.

Consideramos que el concepto de empresa debe ser aprehendido desde la óptica actual de la economía, ya que es un fenómeno que no puede extrapolarse sin perder su naturaleza. En este punto ese parece haber sido el criterio de los redactores del nuevo Código de Derecho Privado argentino, por lo que no debemos considerar que haya habido aquí un olvido u omisión involuntaria, sino todo lo contrario, se ha fundado en la tradición doctrinaria.

Otra cuestión tiene que ver con la concepción de empresa, que deriva del análisis de las normas que regulan particularidades del fenómeno en este cuerpo legal. Allí si podemos intentar interpretaciones, y así lo hicimos, exponiendo que del análisis de los arts. 320 y siguientes inferimos que se admite la concepción más amplia de la misma, como organización, y que el nuevo código viene a expresar una especie de frontera cada vez más borrosa entre las organizaciones típicamente con fines de lucro y destinadas al Mercado, de aquellas que no lo tienen, pero que trasuntan una organización interna.

\section{REFERENCIAS BIBLIOGRÁFICAS}

Besil, A. (2001). Microeconomía básica. Editorial Eudene. Resistencia, Chaco.

Coase, R. H. “El problema del costo social”, en Revista de Estudios Públicos Nro. 1 (1991), Pág. 81-134 (en español), el trabajo original fue publicado en The Journal of Law and Economics $\mathrm{N}^{\circ} 3$ (octubre 1960).

Dell'Elce, Q.P. Comentario referido al nuevo ordenamiento normativo proyectado sobre la temática de los registros y estados contables establecido en el nuevo Código Civil y Comercial de la Nación unificado. Recuperado el 12-07-2015 en: www.consejo.org.ar/congresos/material/ legalylicitud/Dellece.pdf 


\begin{tabular}{|c|c|}
\hline $144<$ & $\begin{array}{c}\text { CRISTIAN RICARDO ABEL PIRIS - VERONICA MARIA LAURA GLIBOTA LANDRIEL } \\
\text { LA EMPRESA EN EL CÓDIGO CIVIL Y COMERCIAL ARGENTINO } \\
\text { Pags. } 126 \text { - } 145\end{array}$ \\
\hline
\end{tabular}

Drucker, P. (1973). La gerencia. Tareas, responsabilidades y prácticas. Editorial El Ateneo. Buenos Aires.

Etcheverry, R. A. (1998). Derecho Comercial y Económico. Parte General. Edito-rial Astrea. Buenos Aires.

Etcheverry, R. A. (2005). Derecho comercial y económico: Parte general. Editorial Astrea. Buenos Aires.

Farinia, J. M. (1997) Contratos comerciales modernos. 2da. Edición. Editorial Astrea, Buenos Aires.

Favier Dubois, E. M. (P) y FAVIER DUBOIS., E. M. (H). 2013. Los sujetos obligados a llevar contabilidad en el texto del código civil y comercial en trámite, en

Errepar DSE, nro. 302, Tomo XXV, Enero 2013.

Favier Dubois, E. M. (P) y FAVIER DUBOIS., E. M. (H). 2014. La derogación del Derecho Comercial por el nuevo Código Civil y Comercial: apariencia y realidad. Recuperado el 02-06-2015 en : www.favierduboisspagnolo.com/trabajos-de-doctrina/la-derogacion-delderecho-comercial-por-el-nuevo-codigo-civil-apariencia-y-realidad/

Fontanarrosa, R. (1986). Derecho Comercial: Parte General. T. I. Zavalía. Buenos Aires.

Garrone, J. (1986). Diccionario Jurídico. Editorial Abeledo-Perrot. Buenos Aires.

Halperín, I. (1994). Curso de derecho comercial. Editorial Depalma. Buenos Aires.

Hernangomez Barahona, J. La empresa como organización: una propuesta de delimitación de su concepto. Recuperado el 22-07-2015 en: dialnet.unirioja.es/descarga/articulo/785516.pdf

Mochón Morcillo, F. y Beker, V. A. (1999). Economía: Principios y aplicaciones. Editorial McGraw-Hill. Madrid.

Posner, R. (1998). Análisis Económico del Derecho. FCE. México.

Vítolo, D. (1998). Iniciación en el estudio del Derecho Mercantil y de la Empresa. Editorial Ad Hoc. Buenos Aires. 


\section{CURRICULUM VITAE}

\section{Verónica Maria Laura Glibota Landriel}

Abogada. Candidata a Doctora en Derecho por la Facultad de Derecho y Ciencias Sociales y Políticas de la UNNE (Tesis Doctoral en estado de aprobación).

Profesora adjunta regular de instituciones de Derecho Privado II, Docente regular de Instituciones de Derecho Privado I, de la Facultad de Ciencias Económicas de la UNNE. Miembro del Instituto Nordeste de la Academia Nacional De Derecho de Córdoba.

Directora del Departamento de Derecho de la Facultad de Ciencias Económicas, UNNE.

Investigadora categorizada.

Miembro de equipo de investigación con proyecto acreditado.

vglibota@eco.unne.edu.ar

\section{Cristian Ricardo A. Piris}

Abogado. Magister en Derecho Privado. Doctor en Derecho.

Profesor Adjunto regular de instituciones de Derecho Privado I de la Facultad de Ciencias Económicas de la UNNE.

Miembro del Instituto Nordeste de la Academia Nacional de Derecho de Córdoba.

Investigador categorizado.

Miembro de equipo de investigación con proyecto acreditado.

cpiris@unne.edu.ar / cristian.piris@gmail.com / twitter.com/cpiris 